\title{
Anisotropic nonlinear problem of infinite order with variables exponents and $\$ \mathrm{~L}^{\wedge} 1 \$$ data
}

\author{
Moussa Chrif ${ }^{1}$ and hakima ouyahya ${ }^{2}$ \\ ${ }^{1}$ Université Moulay Ismail \\ ${ }^{2}$ Université Moulay Ismail Faculté des Sciences
}

November 23, 2020

\begin{abstract}
In this paper, we prove the existence of solutions for the strongly nonlinear equation of the type $\$ \$ A u+g(x, u)=f \$ \$$ where $\$ A \$$ is an elliptic operator of infinite order from a functional Sobolev spaces of infinite order with variables exponents to its dual. $\$ \mathrm{~g}(\mathrm{x}, \mathrm{s}) \$$ is a lower order term satisfying essentially a sign condition on $\mathrm{s}$ and the second term $\mathrm{f}$ belongs to $\$ \mathrm{~L}^{\wedge} 1(\backslash \mathrm{Omega}) \$$.
\end{abstract}

\section{Hosted file}

L1p(x).pdf available at https://authorea.com/users/378170/articles/494716-anisotropicnonlinear-problem-of-infinite-order-with-variables-exponents-and-l-1-data 